\title{
Clinical utility gene card for: Williams-Beuren Syndrome [7q11.23]
}

\author{
Udo Koehler ${ }^{\star, 1}$, Brigitte Pabst ${ }^{2}$, Barbara Pober ${ }^{3,4}$ and Beth Kozel ${ }^{5}$ \\ European Journal of Human Genetics (2014) 22, doi:10.1038/ejhg.2014.28; published online 26 February 2014
}

\section{DISEASE CHARACTERISTICS}

1.1 Name of the disease (synonyms)

Williams-Beuren syndrome, WBS; Williams syndrome, WS.

1.2 OMIM\# of the disease

$\# 194050$.

1.3 Name of the analysed genes or DNA/chromosome segments 7q11.23, 27 unique sequence genes including: NSUN5, TRIM50, FKBP6, FZD9, BAZ1B, BCL7B, TBL2, MLXIPL, VPS37D, DNAJC30, WBSCR22, STX1A, ABHD11, CLDN3, CLDN4, WBSCR27, WBSCR28, ELN, LIMK1, EIF4H, LAT2, RCF2, CLIP2, GTF2IRD1, GTF21, NCF1 and GTF2IRD2 within the Williams critical region. NCF1 and GTF2IRD2 are variably deleted in WBS.

microRNAs: MIR4284, MIR590; long intergenic non-protein coding RNA LINC00035.

1.4 OMIM\# of the gene(s)

ELN, ${ }^{\star} 130160$; GTF2IRD1, ${ }^{\star} 604318 ;$ NCF1, ${ }^{\star} 608512$.

\subsection{Mutational spectrum}

Deletion $7 \mathrm{q} 11.23$ of variable size:

$\sim 1.55 \mathrm{Mb}$ ( $\sim 95 \%$ of cases) to $\sim 1.84 \mathrm{Mb}$ ( $\sim 5 \%$ of cases $).{ }^{1,2}$

Karyotype of a WBS deletion according to HGVS:

chr7.hg19:g.(?_72,644,269)_(74,142,297_?)del.

Rarely, smaller or larger atypical deletions are identified. ${ }^{3}$

Clinical phenotype of the 1.55 and $1.84 \mathrm{Mb}$ deletion are similar but features of the atypical deletions vary depending on the size of deletion and the genes involved.

In non-WBS patients, point mutations within the elastin gene cause similar vascular and connective tissue features to WBS. ${ }^{4}$

For genomic copy number variations and genotype/phenotype correlations, see: https://decipher.sanger.ac.uk/syndrome/3;

http://www.ncbi.nlm.nih.gov/clinvar/;

https://www.iscaconsortium.org/;

http://www.ncbi.nlm.nih.gov/projects/dbvar/ISCA/index.shtml;

http://dgv.tcag.ca/dgv/app/home

All findings should be shared through these databases.

\subsection{Analytical methods}

FISH, ${ }^{5}$ MLPA, qPCR, Microsatellite analysis, chromosomal microarray analysis (CMA), with FISH, MLPA and CMA most commonly employed.

\subsection{Analytical validation}

Parallel analysis of positive and negative controls, depending on analytical method.

\subsection{Estimated frequency of the disease}

(Incidence at birth ('birth prevalence') or population prevalence. If known to be variable between ethnic groups, please report):

$1: 7500-1: 10000 .^{6}$

\subsection{Diagnostic setting}

\begin{tabular}{lll}
\hline & Yes & No \\
A. (Differential) diagnostics & $\square$ & $\square$ \\
B. Predictive testing & $\square$ & $\square$ \\
C. Risk assessment in relatives & $\square$ & $\square$ \\
D. Prenatal & $\square$ & $\square$ \\
\hline
\end{tabular}

Comment:

The vast majority of WBS cases arise due to a sporadic genetic event. It is, therefore, not meaningful to analyse relatives without clinical phenotype. In $25-30 \%$ of the cases, a parent carries an inversion polymorphism ${ }^{7}$ which, however, cannot be detected by the usual WBS analytical methods (FISH, MLPA, CMA).

\section{TEST CHARACTERISTICS}

\begin{tabular}{llll}
\hline Genotype or disease & A: True positive & C: False negative \\
Present $\quad$ Bbsent & & D: False positive & \\
\hline
\end{tabular}

\begin{tabular}{|c|c|c|c|c|}
\hline \multicolumn{5}{|l|}{ Test } \\
\hline \multirow[t]{2}{*}{ Positive } & $A$ & B & Sensitivity: & $A /(A+C)$ \\
\hline & & & Specificity: & $D /(D+B)$ \\
\hline \multirow[t]{2}{*}{ Negative } & C & $\mathrm{D}$ & Positive predictive value: & $A /(A+B)$ \\
\hline & & & Negative predictive value: & $D /(C+D)$ \\
\hline
\end{tabular}

${ }^{1}$ MGZ - Medizinisch Genetisches Zentrum, Munich, Germany; ${ }^{2}$ Institute for Human Genetics, Hannover Medical School, Hannover, Germany; ${ }^{3}$ Department of Pediatrics, Massachusetts General Hospital, Harvard Medical School, Boston, MA, USA; ${ }^{4}$ Department of Medical Sciences, Frank H Netter School of Medicine, Quinnipiac University, North Haven, CT, USA; ${ }^{5}$ Department of Pediatrics, Washington University School of Medicine, St Louis, MO, USA

*Correspondence: Dr U Koehler, MGZ - Medizinisch Genetisches Zentrum, Bayerstrasse 3-5, Munich D-80335, Germany. Tel: +49 (0) 89 3090 886 550; Fax: + 49 (0) 893090886 66; E-mail: koehler@mgz-muenchen.de 
2.1 Analytical sensitivity

(proportion of positive tests if the genotype is present)

Nearly $100 \%$, depending on analytical method.

\subsection{Analytical specificity}

(proportion of negative tests if the genotype is not present)

Nearly 100\%, depending on analytical method.

\subsection{Clinical sensitivity}

(proportion of positive tests if the disease is present)

The clinical sensitivity can be dependent on variable factors such as age or family history. In such cases a general statement should be given, even if a quantification can only be made case by case.

No known phenocopies of WBS have been reported to date. For individuals with classic features of WBS, clinical sensitivity is high. For individuals with fewer features, especially absence of cardiovascular disease, clinical sensitivity is lower.

\subsection{Clinical specificity}

(proportion of negative tests if the disease is not present)

The clinical specificity can be dependent on variable factors such as age or family history. In such cases a general statement should be given, even if a quantification can only be made case by case.

For individuals without features of WBS, specificity is nearly $100 \%$. However, as clinical manifestations are highly variable, clinical specificity for individuals at the mild end of the spectrum (eg, without cardiovascular abnormalities) may be low depending on the quality of the clinical assessment.

2.5 Positive clinical predictive value

(lifetime risk to develop the disease if the test is positive)

$100 \%$, with variable expression of the phenotype.

\subsection{Negative clinical predictive value}

(Probability not to develop the disease if the test is negative)

Assume an increased risk based on family history for a non-affected person. Allelic and locus heterogeneity may need to be considered.

Index case in that family had been tested:

Nearly $100 \%$.

Index case in that family had not been tested:

Cannot be assessed without testing the index case.

\section{CLINICAL UTILITY}

3.1 (Differential) diagnostics: The tested person is clinically affected

(To be answered if in 1.10 'A' was marked)

\subsubsection{Can a diagnosis be made other than through a genetic test?}

\begin{tabular}{|c|c|c|}
\hline No & $\square$ (continue with 3.1 .4 ) & \\
\hline \multirow[t]{7}{*}{ Yes } & $\otimes$ & \\
\hline & Clinically & $凶$ \\
\hline & Imaging & $\otimes$ \\
\hline & Endoscopy & $\square$ \\
\hline & Biochemistry & $\square$ \\
\hline & Electrophysiology & $\square$ \\
\hline & Other (please describe): & \\
\hline
\end{tabular}

\subsubsection{Describe the burden of alternative diagnostic methods to the patient}

A clinical diagnosis can be highly probable in individuals with classic features of $\mathrm{WBS}^{8}$ (eg, supravalvular aortic stenosis, characteristic facial features/neurocognitive profile, hypercalcemia, etc); confirmation using genetic testing is, however, always needed. In individuals with a less classic presentation, the paucity of clinical features may not support clinical suspicion of the disorder so that genetic testing both suggests and confirms the diagnosis. Evaluation would include, but is not restricted to a cardiology examination with echocardiogram and EKG, laboratory evaluation for calcium abnormalities, clinical examination by a clinician experienced with WBS and neurocognitive assessment.

3.1.3 How is the cost effectiveness of alternative diagnostic methods to be judged?

As the clinical diagnosis of WBS can be suggested for only a subset of individuals, this is not a cost-effective diagnostic method.

\subsubsection{Will disease management be influenced by the result of a genetic test?}

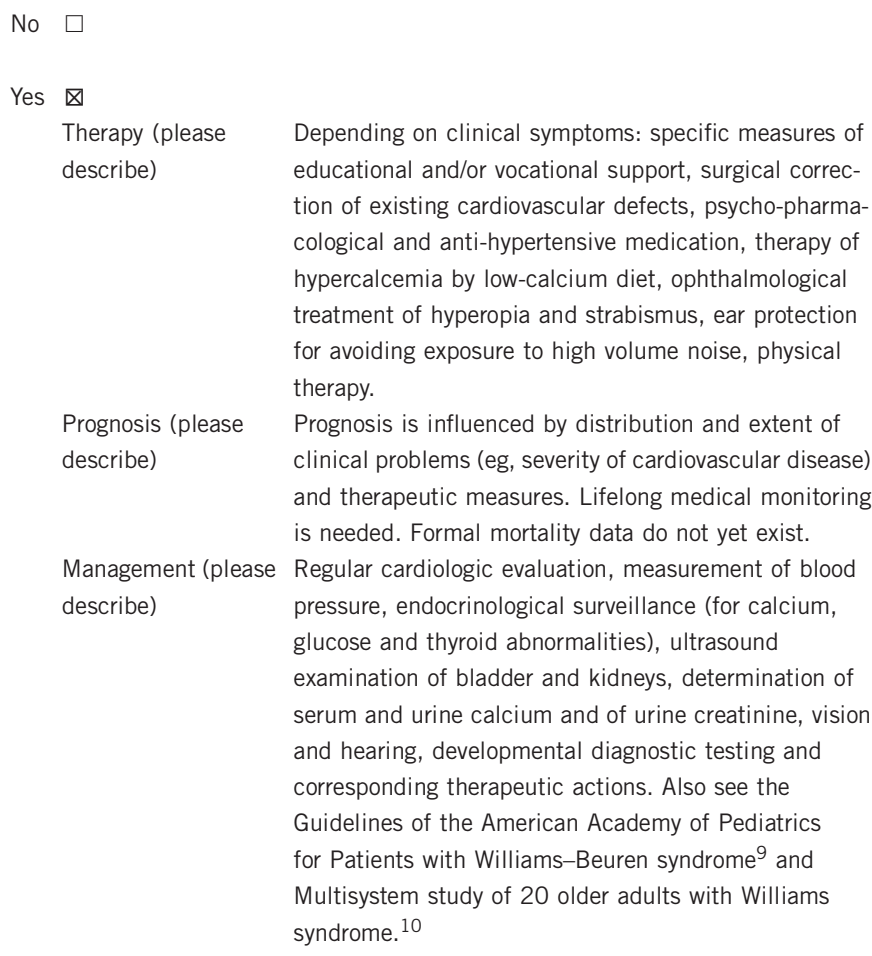

3.2 Predictive setting: the tested person is clinically unaffected but carries an increased risk based on family history

(To be answered if in 1.10 ' $\mathrm{B}$ ' was marked)

\subsubsection{Will the result of a genetic test influence lifestyle and prevention?}

If the test result is positive (please describe) Yes, see 3.1.4.

If the test result is negative (please describe) Not specifically. The lifestyle will be, however, influenced by the underlying disease.

3.2.2 Which options in view of lifestyle and prevention does a person at-risk have if no genetic test has been done (please describe)?

In the absence of genetic testing, individuals with classic features of WBS should be managed according to guidelines for health maintenance in WBS. ${ }^{9,10}$ Such guidelines include staying active and preventing obesity (eg, to minimize risk of developing diabetes and osteopenia). 
3.3 Genetic risk assessment in family members of a diseased person (To be answered if in 1.10 'C' was marked)

\subsubsection{Does the result of a genetic test resolve the genetic situation in that family?}

Yes, if no other family members are similarly affected. In the unlikely event that family members are similarly affected, genetic test results from them are needed to resolve the situation in the family.

\subsubsection{Can a genetic test in the index patient save genetic or other} tests in family members?

Yes, if no other family members are similarly affected.

3.3.3 Does a positive genetic test result in the index patient enable a predictive test in a family member?

Yes.

\subsection{Prenatal diagnosis}

(To be answered if in 1.10 ' $\mathrm{D}$ ' was marked)

\subsubsection{Does a positive genetic test result in the index patient enable a} prenatal diagnosis?

Yes.

\section{IF APPLICABLE, FURTHER CONSEQUENCES OF TESTING}

Please assume that the result of a genetic test has no immediate medical consequences. Is there any evidence that a genetic test is nevertheless useful for the patient or his/her relatives? (Please describe).

Yes. Doing this test may lessen the diagnostic odyssey that potentially includes more invasive testing. Diagnosis enables family members and caregivers to have realistic expectations about their child's growth, health and development. Diagnosis allows optimization of specific therapies (diet, preventive examinations, supportive measures such as assistance in school and therapeutic services).

\section{CONFLICT OF INTEREST}

The authors declare no conflict of interest.

\section{ACKNOWLEDGEMENTS}

This work was supported by EuroGentest2 (Unit 2: 'Genetic testing as part of health care'), a Coordination Action under FP7 (Grant Agreement Number 261469) and the European Society of Human Genetics.

1 Bayes M, Magano LF, Rivera N, Flores R, Perez Jurado LA: Mutational mechanisms of Williams-Beuren syndrome deletions. Am J Hum Genet 2003; 73: 131-151.

$2 \mathrm{Wu} Y \mathrm{Y}$, Sutton VR, Nickerson $\mathrm{E}$ et al: Delineation of the common critical region in Williams syndrome and clinical correlation of growth, heart defects, ethnicity, and parental origin. Am J Med Genet 1998; 78: 82-89.

3 Schubert C: The genomic basis of the Williams-Beuren syndrome. Cell Mol Life Sci 2009; 66: 1178-1197

4 Metcalfe K, Rucka AK, Smoot $L$ et al: Elastin: mutational spectrum in supravalvular aortic stenosis. Eur J Hum Genet 2000; 8: 955-963.

5 Nickerson E, Greenberg F, Keating MT, McCaskill C, Shaffer LG: Deletions of the elastin gene at $7 \mathrm{q} 11.23$ occur in approximately $90 \%$ of patients with Williams syndrome. Am J Hum Genet 1995; 56: 1156-1161.

6 Stromme P, Bjornstad PG, Ramstad K: Prevalence estimation of williams syndrome. J Child Neurol 2002; 17: 269-271.

7 Morris CA, Mervis CB, Osborne LR: Frequency of the 7q11.23 inversion polymorphism in transmitting parents of children with williams syndrome and in the general population does not differ between North America and Europe. Mol Cytogenet 2011; 4: 7.

8 Pober BR: Williams-Beuren syndrome. N Engl J Med 2010; 362: 239-252.

9 American academy of pediatrics. Health care supervision for children with Williams syndrome. Pediatrics 2001; 107: 1192-1204.

10 Cherniske EM, Carpenter TO, Klaiman C et al: Multisystem study of 20 older adults with Williams syndrome. Am J Med Genet A 2004; 131: 255-264. 